\title{
ANÁLISES DA ÁGUA E SUA CONTAMINAÇÃO POR MICRO-ORGANISMOS INFLUENCIANDO A VIABILIDADE PARA O CONSUMO HUMANO
}

\section{WATER RATIOS AND MICROORGANISMS CONTAMINATION INFLUENCING THEIR VIABILITY FOR HUMAN CONSUMPTION}

\author{
Alan Carlos De Oliveira Castro ${ }^{1}$, Thales Caetano de Oliveira², Matheus Vinicius Abadia Ventura², \\ Germanna Gouveia Tavares ${ }^{3}$
${ }^{1}$ Doutorando em Ciências Agrárias pelo Instituto Federal Goiano - campus Rio Verde - alan.agrogsia@gmail.com
${ }^{2}$ Mestrando em Ciências Agrárias pelo Instituto Federal Goiano - campus Rio Vere
${ }^{3}$ Graduanda em Agronomia pelo Instituto Federal Goiano - campus Rio Verde

\begin{abstract}
Resumo: A água é essencial para a vida e o elemento indispensável para a manutenção da mesma. O objetivo deste trabalho foi avaliar $\mathrm{pH}$, condutividade elétrica e contaminação por micro-organismos. Foram coletadas amostras, onde realizaram diluição em solução salina de $0,85 \%$ até a concentração de 5 e plaqueados em triplicata em método pour-plate em 6 diferentes meios de cultura: BDA, CLED, Agar Bromo Thymol, Agar nutritivo, Agar Sabouraud, GELP e GL, encubados sete dias em estufa bacteriológica a $28^{\circ} \mathrm{C}$. Para análise de $\mathrm{pH}$ foi utilizado medidor de PH de Bancada - Q400AS QUIMIS, para condutividade elétrica, Condutivimetro portátil Quimis modelo Q795P 9UDC (bateria) - OW. Ao final todos os meios de cultura, exceto Sabouraud tornaram possível o isolamento de bactérias e fungos, todas as amostras desenvolveram micro-organismos, as do manancial Ribeirão Anda Só e água mineral demonstraram mesmo padrão de contaminação, $\mathrm{pH}$ e Condutividade elétrica, com isso ambas estão aptas para consumo.
\end{abstract}

Palavras - chave: contaminação hídrica, $\mathrm{pH}$, Condutividade elétrica.

Abstract: Water is essential for life and indispensable element for maintenance thereof. The objective of this study was to evaluate $\mathrm{pH}$, electrical conductivity and contamination by microorganisms. Samples were collected and dilution was performed in $0.85 \%$ saline to a concentration of -5 and plated in triplicate in pour plate method, on 6 different culture medium: BDA, CLED, Agar Bromo thymol. Nutrient Agar, Sabouraud Agar, GELP and GL, hatched for seven days in a bacteriological incubator for $28^{\circ} \mathrm{C}$. For analysis of $\mathrm{pH}$ was used Bench $\mathrm{pH}$ meter - Q400AS QUIMIS and for electrical conductivity, Conductivity portable Quimis model Q795P 9UDC (drums) - OW. At the end of all culture medium, except Sabouraud, made possible the isolation of bacteria and fungi, all samples developed microorganisms, the sample from Spring Anda Só and mineral water showed same pattern of contamination, and likeness in $\mathrm{pH}$ and electric conductivity, thereby both suitable for consumption. Keywords: Water contamination, $\mathrm{pH}$, Electrical Conductivity.

\section{INTRODUÇÂO}

A água é essencial para a vida, além de ser o elemento indispensável para a manutenção da mesma, não apenas por suas características, mas pelo fato de que nenhum processo metabólico ocorre sem sua ação direta ou indireta (DE SOUZA et al. 2014). Nestas condições, torna-se imprescindível que sua presença no ambiente esteja em quantidade e qualidade apropriadas para sua futura utilização (ESTEVES, 1998; BRAGA et AL. 2002; REBOUÇAS, 2002).
Por isso deve- se atentar ao uso de destino da água, levando em conta os fatores que podem agir negativamente na qualidade da água, pois se consumida sem nenhum tratamento ocasiona sérios agravantes a saúde, servindo de veículo para vários agentes biológicos e químicos. A baixa qualidade das águas naturais é um dos problemas mundiais mais graves. No Brasil, cerca de $87 \%$ dos municípios tem acesso à água canalizada e de qualidade para consumo, porém apenas 55\% dispõem de rede de esgotamento sanitário, e 
naqueles onde existe rede de esgoto, somente 28\% possuem um sistema de tratamento (IBGE, 2010).

A agricultura e pecuária são de extrema importância para a produção de alimentos. Contudo, a deposição de resíduos agrícolas e animais têm resultado em alterações ambientais (CARVALHO et al, 2000).Vários fatores podem comprometer a qualidade da água, como o destino final do esgoto doméstico e industrial em fossas e tanque sépticos, a disposição inadequada de resíduos sólidos urbanos e industriais, postos de combustíveis e de lavagem e a modernização da agricultura, representam fontes de contaminação das águas por bactérias e vírus patogênicos, parasitas, substâncias orgânicas e inorgânicas (DA SILVA; DE ARAÚJO, 2003). Cemitérios também causam impacto devido à geração e percolação pelo solo de um líquido escuro chamado necrochorume. Esse líquido é resultado da decomposição dos corpos e contem substâncias orgânicas, inorgânicas e micro-organismos, podendo contaminar o solo e os recursos hídricos localizados nas proximidades em lugares inadequados (SILVA; MALAGUTTTI FILHO, 2010).

Para as condições do Brasil, não se tem quantificado o quanto esses poluentes contribuem para a degradação dos recursos hídricos do pais. Nos Estados Unidos, no entanto, admite-se que $50 \%$ a $60 \%$ da carga poluente que contamina os lagos e rios, respectivamente, são provenientes da agricultura (GBUREK, SHARPLEY 1998). (MORAES; JORDÃO, 2002) enfatizam que os ambientes aquáticos são utilizados em todo o mundo com distintas finalidades, entre as quais se destacam o abastecimento de água. Segundo Tucci
(2008), o Brasil passa por um processo de urbanização, que gera problemas relacionados com a infraestrutura de água no ambiente urbano.

A água para consumo humano pode ser obtida de diferentes fontes, o melhoramento dos serviços públicos de abastecimento de água reflete uma melhoria na saúde da população (BARCELLOS, 2006). A garantia do consumo humano de água potável, livre de microorganismos patogênicos, de substâncias e elementos químicos prejudiciais à saúde, constituise em ação eficaz de prevenção das doenças causadas pela água (DA SILVA; DE ARAÚJO, 2003). Assim, a política normativa nacional de uso da água, como consta na resolução número 20 do CONAMA (Conselho Nacional do Meio Ambiente), procurou estabelecer parâmetros que definem limites aceitáveis de elementos estranhos, considerando os diferentes usos (MERTEN; MINELLA, 2002).

Segundo a Organização das Nações Unidas (ONU), 1,1 bilhão de habitantes não têm acesso à água tratada e cerca de 1,6 milhão de pessoas morrem no mundo todos os anos em razão de problemas de saúde decorrentes da falta desse recurso. O país possui $12 \%$ das reservas de água doce disponíveis no mundo, sendo que a Bacia Amazônica concentra 70\% desse volume (portal Brasil 2015). A Organização Mundial de Saúde (OMS) estima que 25 milhões de pessoas no mundo, morrem, por ano devido a doenças transmitidas pela água, como cólera e diarreias. A OMS indica que nos países em desenvolvimento $70 \%$ da população rural e $25 \%$ da população urbana não dispõem de abastecimento adequado de água potável (ZANCUL M.S, 2006). 
O objetivo do presente trabalho foi verificar a presença e o crescimento de unidades formadoras de colônia em diferentes meios de cultivo como indicadores de qualidade da água em diversas fontes e alguns coeficientes químicos e físicos, levando em consideração a água tratada e mineral, água de afluentes, estação de tratamento de esgoto do município de Goianésia, na região do vale do são patrício em Goiás, assim como as micro bacias nas quais estão inseridos e que possuem intensa atividade pecuária e agrícola, foi testado a influencia desses fatores na mesma.

\section{MATERIAIS E MÉTODOS}

As amostras foram retiradas dos Ribeirões Ando só e Laranjeira, os dois são tributários do Rio Tocantins afluente da Bacia Tocantins, e a lagoa princesa do vale. A área amostral dos dois ribeirões e da lagoa é margeada por Latossolo Vermelho acriférrico (LV) predominante em Goianésia(GO), situada na latitude $15^{\circ} 10^{\prime} \mathrm{S}$ e longitude $49^{\circ} 15^{\prime} \mathrm{W}$, com clima tropical de savana com verão chuvoso e inverno seco, temperatura média diária intercalando entre $22^{\circ}$ a $26^{\circ}$ graus.

As análises foram realizadas no laboratório de Microbiologia do Solo da Faculdade Evangélica de Goianésia. As amostras foram retiradas de diferentes pontos no município, situado no vale do São patrício, em Goiás. Foram analisadas amostras de quatro afluentes sendo eles: Ribeirão Anda Só, responsável pelo abastecimento de água potável do município, Ribeirão Laranjeira, Lagoa Princesa do Vale, e saída da ETE - estação de tratamento de esgoto do município de Goianésia, como tratamento comparativo foi analisado água mineral comercial (Tabela 1).

Tabela 1. - Localização e descrição dos pontos de coleta estudados no município de Goianésia.

\begin{tabular}{llll}
\hline Pontos & Coordenada Geográfica & Município & Descrição \\
P1 & $(-15.33108316-49.06891108)$ & Goianésia & Ribeirão Anda Só \\
P2 & $(-15.306415,-40.06962773)$ & Goianésia & Ribeirão Laranjeira \\
P3 & $(-15.309303,-49.109003)$ & Goianésia & Lagoa P. do Vale \\
P4 & $(-15.31795022,-49.09427404)$ & Goianésia & ETE \\
P5 & T. comparativo & Goianésia & Água Mineral \\
\hline
\end{tabular}

\section{Amostragem}

As amostras de água foram obtidas com auxilio de um balde, onde foi feita a coleta de vários pontos no mesmo local e uniformizadas dentro do mesmo, depois utilizou-se uma seringa esterilizada de $250 \mathrm{~mL}$ para captura das amostras de cada tratamento. Foi realizada a diluição sucessiva em solução salina de $0,85 \%$ ate a concentração de -5 e plaqueados em triplicata, por método pour-plate em seis diferentes meios de cultura: BDA, C.L.E.D. ágar Bromo Thymol. Agar nutritivo, Agar Sabouraud, GELP e GL. E encubados durante sete dias em estufa bacteriológica por $28^{\circ} \mathrm{C}$. Foi quantificado o número de unidades formadoras de colônias nos meios testados. Para os testes físico-químicos foram coletadas cinco amostras de cada tratamento, para análise de $\mathrm{PH}$ e condutividade elétrica. O PH foi medido utilizando um medidor de PH de Bancada - Q400AS QUIMIS, o medidor foi calibrado com soluções tamponadas de $\mathrm{PH}$ 4,01, 6,86 e 9,18, e para condutividade elétrica foi 
utilizado o Condutivimetro portátil Quimis modelo Q795P 9UDC (bateria) - OW. Sendo estas duas últimas análises realizadas no Laboratório de solos da Faculdade Evangélica de Goianésia (FACEG).

\section{Análises estatísticas}

A análise dos dados microbiológicos foi feita de forma descritiva, onde presença e ausência de unidades formadoras de colônias de fungos e bactérias foi demonstrada na Tabela 2. Para os parâmetros de $\mathrm{PH}$ e Condutividade Elétrica, a análise estatística dos dados foi realizada por delineamento inteiramente casualisado onde as condições de estudos eram completamente uniformes, após a ANAVA (análise de variância) foi aplicado o teste de F para a análise da diferença entre as medias, após teste de comparação de média onde foi utilizado o teste de Tukey ao nível de $5 \%$ de probabilidade.

\section{RESULTADOS E DISCUSSÃO}

Devido à grande produção de resíduos líquidos de origem animal e vegetal altamente poluentes lançados ao solo e nos cursos de água sem tratamento prévio (EMBRAPA, 1998). A degradação dos mananciais, proveniente do deflúvio superficial agrícola vem aumentando gradativamente conforme os anos. As técnicas relacionadas com a redução do deflúvio superficial são baseadas na manutenção da água e melhoria da qualidade da estrutura do solo (MERTEN; MINELLA, 2002).

Algumas técnicas e equipamentos destacamse para o tratamento ou disposição dos resíduos de animais, como: biodigestores, esterqueiras, bioesterqueiras e etc (SILVA; MAGALHÃES, 2001). Segundo Borges et al. 2003 alem dessas técnicas a canalização, recuperação e tratamento paisagístico dos córregos da zona urbana, recuperação dos recursos naturais degradados por ação do homem ou da natureza, afastamento do esgoto associados a expansão do município. Visando a melhoria da qualidade ambiental através do controle da poluição da água e do solo são medidas para recuperar a qualidade hídrica da região. Segundo Tsutiya (2006), a concepção dos sistemas de abastecimento de água é extremamente dependente do porte da cidade, da topografia, e de sua posição em relação aos mananciais. De um modo geral, os sistemas são constituídos dos seguintes elementos:

- Manancial: corpo de água superficial ou subterrâneo, do qual é retirada a água para o abastecimento populacional;

- Captação: conjunto de estruturas e dispositivos, construídos ou montados junto ao manancial, para a retirada de água destinada ao sistema de abastecimento;

- Estação Elevatória: conjunto de obras e equipamentos para recalcar a água para a unidade seguinte;

- Adutora: canalizações para conduzir água entre unidades que precedem a rede de distribuição;

- Estação de Tratamento de Água (ETA): unidade na qual a água é tratada para atender às normas e padrões de potabilidade vigentes no país;

- Reservatório: unidade do sistema na qual a água tratada é armazenada para ser distribuída aos consumidores; 
- Rede de Distribuição: tubulações e acessórios para levar água potável até os consumidores.

Nas análises microbiológicas foi constatada a presença de unidades formadoras de colônias de fungos e bactérias em todos os meios testados (Tabela 2). Vimos que algumas fontes já previstas estavam contaminadas, pois estão em contato com vários agentes biológicos e químicos que representam fontes de contaminação das águas, como por exemplo: bactérias, vírus patogênicos, parasitas, substâncias orgânicas e inorgânicas. Os aspectos envolvidos nessa relação são múltiplos e nem sempre se baseiam em associações diretas (DA SILVA; DE ARAÚJO, 2003).

No caso da água mineral, o fato de ser encontrada uma amostra contaminada, pode permitir relatar que sua contaminação pode ter ocorrido durante a fase de captação e processamento do produto (VILLELA, 2010). Buscando a qualidade da água, foi feito a avaliação microbiológica pela contagem de colônias totais semeadas em seis meios de cultura, segundo os critérios de assepsia recomendados na literatura. Segundo Villela et al. 2010 em seu estudo constatou que de 18 amostras de diferentes marcas de água mineral comercializadas em Marília, apenas 5,5\% estavam contaminadas por coliformes totais, sendo que $94,5 \%$ estavam aptas para consumo. Com esse trabalho tem-se a importância da pureza da água para o consumo humano, levando em consideração os riscos de contaminantes, pois mesmo a água mineral se mostrou contaminada. Tais trabalhos demonstram que falhas na higiene durante o processamento dos produtos merecem atenção e fiscalização, além de servir como material de apoio para futuras análises (VILLELA, 2010). Apesar do aumento de evidências acerca dos efeitos nocivos à saúde provenientes do uso de água fora dos padrões adequados para consumo humano e animal, os danos à saúde decorrentes do consumo de água contaminada são difíceis de serem avaliados e mensurados adequadamente (Da Silva; De Araújo, 2003).

Foi observado os fatores externos que afetam os valores de $\mathrm{pH}$ da água, nestas fontes a indícios do acúmulo de substâncias como bicarbonatos e carbonatos em sua composição, conhecidas como soluções tamponadoras. Sua menor concentração de íons $\mathrm{H}+$ pode ser decorrente do tipo de solo proveniente da formação da cidade de Goianésia e da ausência de ácidos minerais e orgânicos, dissolvidos do material de origem alóctone (adubos) e/ou autóctone. A cobertura vegetal original dessa região era Cerrado e atualmente predomina a canade-açúcar, nos testes feitos a media geral $(\mathrm{MG})$ foi de 7,91 e o CV \% (coeficiente de variação em \%) $=0,84$ 
Tabela 2 - Presença (+) e ausência (-) de unidades formadoras de colônias de fungos e bactérias em afluentes do município de Goianésia, Goiás.

\begin{tabular}{|c|c|c|c|}
\hline Fonte & $\begin{array}{ll}\text { Meio } & \text { de } \\
\text { Cultura } & \\
\end{array}$ & Bácteria & Fungo \\
\hline \multirow{6}{*}{$\begin{array}{l}\text { Lago Princesa do } \\
\text { Vale }\end{array}$} & $\mathrm{BDA}$ & - & + \\
\hline & GL & - & + \\
\hline & GELP & - & + \\
\hline & Agar Nutriente & + & + \\
\hline & Sabouraud & - & - \\
\hline & Cled & + & + \\
\hline \multirow{6}{*}{$\begin{array}{l}\text { Estação } \\
\text { Tratamento } \\
\text { Esgoto }\end{array}$} & BDA & - & + \\
\hline & GL & - & + \\
\hline & GELP & - & + \\
\hline & Agar Nutriente & + & - \\
\hline & Sabouraud & - & - \\
\hline & Cled & + & + \\
\hline \multirow{6}{*}{ Ribeirão Anda Só } & $\mathrm{BDA}$ & - & - \\
\hline & GL & - & - \\
\hline & GELP & - & - \\
\hline & Agar Nutriente & + & - \\
\hline & Sabouraud & - & - \\
\hline & Cled & + & + \\
\hline \multirow{6}{*}{$\begin{array}{l}\text { Ribeirão } \\
\text { Laranjeira }\end{array}$} & $\mathrm{BDA}$ & - & - \\
\hline & GL & - & + \\
\hline & GELP & - & + \\
\hline & Agar Nutriente & - & - \\
\hline & Sabouraud & - & - \\
\hline & Cled & - & - \\
\hline \multirow{6}{*}{ Água Mineral } & $\mathrm{BDA}$ & - & - \\
\hline & GL & - & - \\
\hline & GELP & - & + \\
\hline & Agar Nutriente & + & - \\
\hline & Sabouraud & - & - \\
\hline & Cled & + & - \\
\hline
\end{tabular}

Onde as medias R. Anda Só, Água Mineral e R. laranjeira não se diferem estatisticamente, já as medias ETE e L. P. Vale tem uma diferença significativa entre ambas e essa diferença é mais discrepante em relação as demais (Tabela 3).

Em trabalhos semelhantes verificou-se que os menores valores de $\mathrm{pH}$ ocorreram sempre entre 4,4 e 4,9, resultados semelhantes aos obtidos por (AMARAL, 1992) E (SAAEJ, 2000). No Ribeirão da Onça o parâmetro foi de 5,6 a 6,5 embora não atingindo valores neutros, teve esse aumento no verão (CARVALHO, 2000). Segundo Derísio 1992, na cidade Feira de Santana (BA) Foi também elevado o percentual de amostras com PH ácido, menor que 6,0 .

$\mathrm{Na}$ cidade de Goianésia - GO a água destinada ao tratamento pela (SANEAGO 2008) durante todo ano se manteve dentro dos parâmetros para consumo de 6,0 a 9,5, a acidez da água pode contribuir para a corrosão das estruturas das instalações hidráulicas, adicionando constituintes à água (DA SILVA, DE ARAÚJO; 
2003). As maiores alterações neste indicador são provocadas por despejos de origem industrial (DERÍSIO, 1992), A disposição final de resíduos industriais em rios ou lagoas pode estar contribuindo para a acidificação nas áreas investigadas.

Tabela 3 - Media Geral do pH para cada Tratamento coletado.

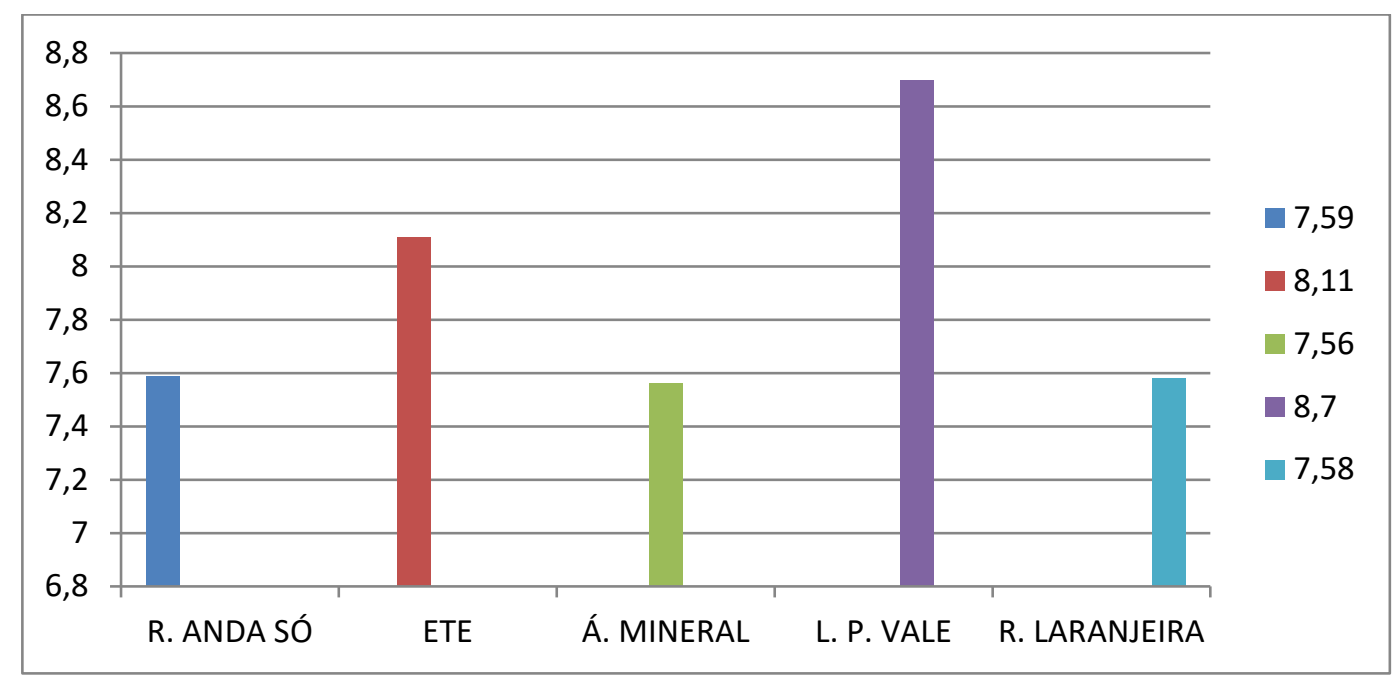

$\mathrm{Na}$ análise de Condutividade elétrica se observa os sais minerais presentes na água, devido ao consumo de alguns elementos nos processos respiratórios da comunidade hídrica, principalmente se for material orgânico, associados ao processo de mineralização de material orgânico, ocasionam aumento na condutividade elétrica da água (TOLEDO; NICOLELLA, 2002).Na medida em que se diminui o teor de água, aumenta os sais concentração na água. (BACCARO, 2006). Nos testes feitos sob cinco tratamentos foi constatado que as amostras que demonstraram maiores índices de condutividade elétrica em relação as demais foram a ETE e R. Laranjeira.a L. P. Vale ficou acima das duas restantes, já as demais não tiveram diferença significativa (Tabela 4). Pelo gráfico observasse que os afluentes que contém maiores concentrações de sais minerais em forma de matéria orgânica são a ETE e o R. Laranjeira onde e depositado o esgoto tratado de Goianésia, Alem das deposições ocasionas pela agricultura da região, o Ribeirão Anda Só e o manancial de abastecimento da cidade, na análise apresentou os mesmos parâmetros da Água mineral. A condutividade elétrica pode variar de acordo com a temperatura e a concentração total das substancias ionizadas dissolvida. 
Tabela 4 - Media Geral de cada Tratamento sob a condutividade elétrica.

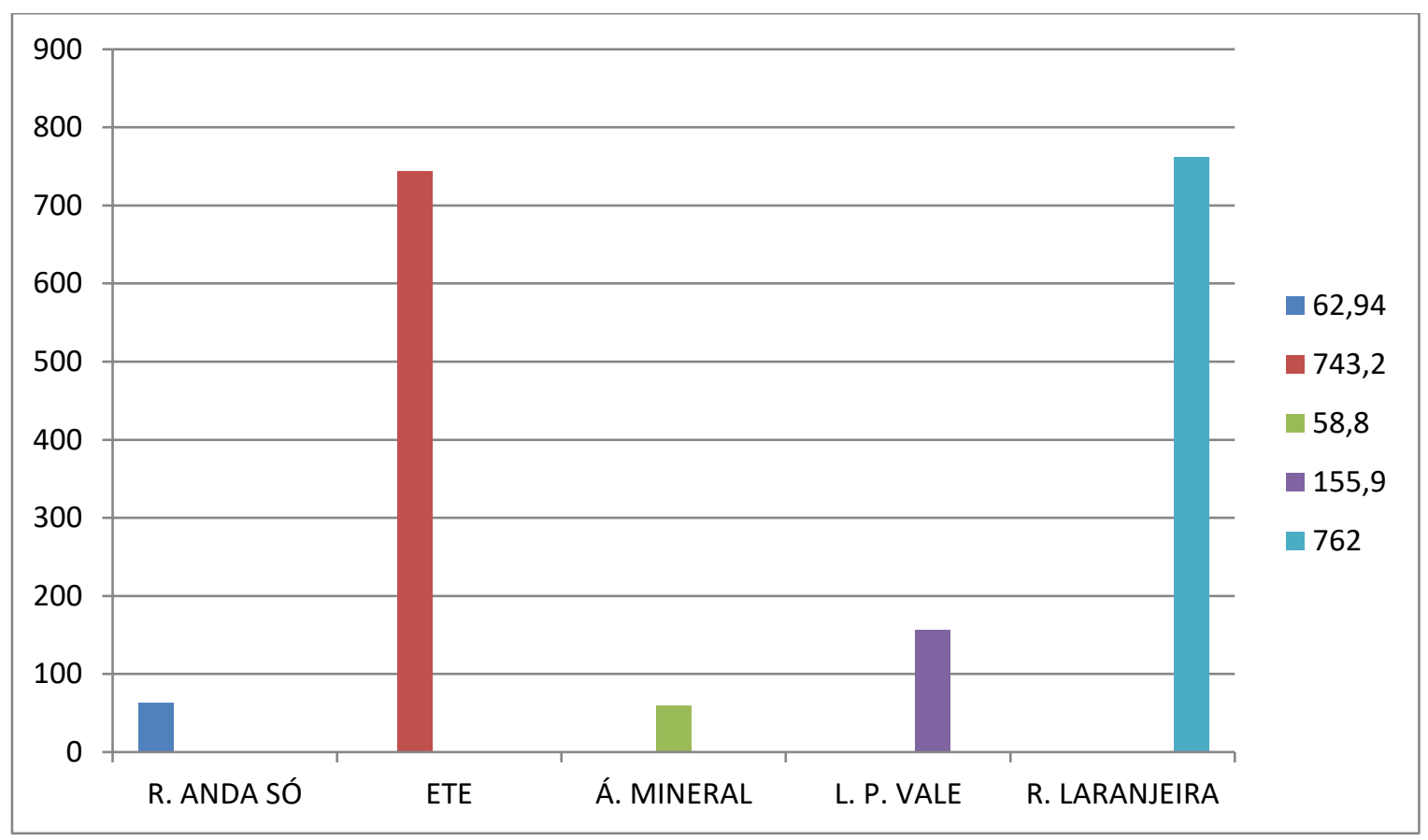

\section{CONCLUSÃO}

Em todos os meios de cultura, exceto Sabouraud, foi possível o isolamento de bactérias e fungos, com isso todas as amostras desenvolveram micro-organismos. As amostras do manancial R. Anda Só e água mineral demonstraram o mesmo padrão de contaminação, irrelevante para a saúde humana.

Fungos e bactérias foram detectados, predominantes, nos meios CLED e Agar nutriente e encontradas em maior abundância no tratamento da Lagoa Princesa do Vale. Foi constatado que o $\mathrm{pH}$ do ribeirão que abastece a cidade é semelhante ao da água mineral, portanto, está dentro dos padrões aceitáveis, em locais com maior teor de matéria orgânica o $\mathrm{pH}$ se tornou mais alcalino.

Os tratamentos que demonstraram maior condutividade elétrica foram a ETE e o R. Laranjeira devido ao seu alto teor de sais dissolvidos na água, em contrapartida o manancial Anda Só alcançou as mesmas medias da água mineral.

\section{REFERÊNCIAS BIBLIOGRÁFICAS}

AMARAL, L. A. do. Influência da precipitação pluviométrica nas características bacteriológicas, físicas e químicas da água de diferentes mananciais de abastecimento da cidade de Jaboticabal, SP. 113 p. Tese (Doutorado em Saúde Pública). Faculdade de Saúde Pública, Universidade de São Paulo, São Paulo. 1992.

BACCARO, K; DEGORGUE, M; LUCCA, M; PICONE, L; ZAMUNER, E; ANDREOLI, Y. Calidad del agua para consumo humano y Riego en muestras del cinturón hortícola de mar del plata, INTA, Argentina, RIA, v. 35, n. 3 p. $95-110,2006$.

ROCHA, C. M. B. M. da; RODRIGUES, L. dos S.; COSTA, C. C.; OLIVEIRA, P. R. de; SILVA, I. J. da, JESUS, É. F. M. de; \& ROLIM, R. G. Avaliação da qualidade da água e percepção higiênico-sanitária na área rural de Lavras, Minas Gerais, Brasil, 1999-2000 Water quality evaluation in rural areas of Lavras, Minas Gerais, Brazil, 1999-2000. Cad. Saúde Pública, v. 22, n. 9, p. 1967-1978, 2006. 
BORGES, M. J; GALBIATTI, J. A; FERRAUDO, A. S. Monitoramento da Qualidade Hídrica e Eficiência de Interceptores de Esgoto em Cursos d'Água Urbanos da Bacia Hidrográfica do Córrego Jaboticabal. RBRH - Revista Brasileira de Recursos Hídricos. Volume 8 n.2, p.161171, 2003.

BRAGA, B.; HESPANHOL, I.; CONEJO, J. G. L.; MIERZWA, J. C.; BARROS, M. T. L. de.; SPENCER, M.; PORTO, M.; NUCCI, N.; JULIANO, N.; EIGER, S. Introdução à engenharia ambiental: o desafio do desenvolvimento sustentável. 2. ed. São Paulo: Pearson Prentice Hall, 2005. reimpressão 2006. 318 p.

BRASIL. CONAMA. Resolução n. ${ }^{\circ}$ 237, de 19 de dezembro de 1997. Diário Oficial [da] República Federativa do Brasil. Brasília, 22 dez. 1997. Disponível em: < http://www.mma.gov.br/port/conama/legia bre.cfm?codlegi=237>. Acesso em: 26 de agosto de 2015.

BRASIL. Ministério da Saúde. Manual prático de análise de água. Brasília: Funasa, 2004. 120p. Disponível em: < http://www.funasa.gov.br/site/wpcontent/files_mf/manual_pratico_de_analise _de_agua_2.pdf $>$. Acesso em: 17 de agosto de 2015.

CARVALHO, A. R.; SCHLITTLER, F. H. M.; TORNISIELO, V. L.. "Relações da atividade agropecuária com parâmetros físicos químicos da água." Química Nova, v. 23 n. 5 p.618622, 2000.

DA SILVA, R. de C. A.; DE ARAÚJO, T. M. Qualidade da água do manancial subterrâneo em áreas urbanas de Feira de Santana (BA). Ciênc. saúde coletiva, v.8 n.4 São Paulo, 2003

DERÍSIO J. C. Introdução ao controle de poluição ambiental. CETESB-Companhia de Tecnologia de Saneamento Ambiental, São Paulo, 1992.

DE SOUZA, J. R.; MORAES, M. E. B.; SONADA, S. L.; SANTOS, H. C. R. G. A
Importância da Qualidade da Água e os seus Múltiplos Usos: Caso Rio Almada, Sul da Bahia, Brasil. REDE-Revista Eletrônica do Prodema, v. 8, n. 01, 2014.

EMPRESA BRASILEIRA DE PESQUISA AGROPECUÁRIA - EMBRAPA. Centro Nacionalde Pesquisa em Aves e Suínos. Manejo de dejetos de suínos. Concórdia, 1998. 31p. (Boletim Informativo de Pesquisa, 11).

ESTEVES, F. A. Fundamentos de limnologia. 2 ed. Rio de Janeiro: Interciência, 1998.

GBUREK, W. J.; SHARPLEY, A. N. Hydrologic controls on phosphorus loss from upland agricultural watersheds. Journal of Environmental Quality, v. 27, n. 2, p. 267277, 1998.

INSTITUTO BRASILEIRO DE GEOGRAFIA E ESTATISTICA - IBGE. Pesquisa nacional do saneamento básico. Rio de Janeiro, 2010.

Disponível em:

<https://www.ibge.gov.br/estatisticasnovoportal/multidominio/meioambiente/9073-pesquisa-nacional-desaneamento-basico.html>. Acesso em: $07 \mathrm{de}$ agosto de 2015.

MERTEN, G. H.; MINELLA, J. P. Qualidade da água em bacias hidrográficas rurais: um desafio atual para a sobrevivência futura. Agroecologia e Desenvolvimento Rural Sustentável, v. 3, n. 4, p. 33-38, 2002.

MORAES, D. S. L.; JORDÃO, B. Q. Degradação de recursos hídricos e seus efeitos sobre a saúde humana. Rev. Saúde Pública. v. 36, n. 3, p. 370-4, 2002.

PORTAL BRASIL, CIÊNCIA E TECNOLOGIA. Saiba mais sobre água, consumo consciente e recursos hídricos no Brasil. Disponível em: $<$ http://www.brasil.gov.br/ciencia-etecnologia/2010/10/agua-e-consumoconsciente $>$. Acesso em: 28 de agosto de 2015.

REBOUÇAS, A. da C. Água doce no mundo e no Brasil. In: REBOUÇAS, A. da C.; BRAGA, 
B.; TUNDISI, J. G. Águas doces no Brasil capitais ecológicos uso e conservação. 3ed, São Paulo: Escrituras, 2002. p. 269 - 324.

SAAEJ - SERVIÇO AUTÔNOMO DE ÁGUA
E ESGOTO DE JABOTICABAL. Relatórios técnicos. Jaboticabal: a Autarquia. 2010. Disponível em: < http://www.saaej.sp.gov.br/lei2550.html>. Acesso em: 31 de agosto de 2015.

SANEAGO. SANEAMENTO DE GOIAS S.A., GOIAS. Secretaria Municipal de Goianésia. Relatório Anual da Qualidade da Água Distribuída. 2008.

SILVA, E. T.; MAGALHÃES, C. S. Controle de poluição de atividades pecuárias. Informe Agropecuário, Belo Horizonte, v. 22, n. 210, p. 62-76, 2001.

SILVA, R. W. C.; MALAGUTTI FILHO, W. Application of electrical imaging in the study of contamination from cemeteries. Geociências, v. 29, p. 343-354, 2010.

SOLER, E. M.; DE TOLEDO, F. M. B.; DOS SANTOS, M. O.; ARENALES, M. N. Otimização dos custos de energia elétrica na programação da captação, armazenamento e distribuição de água. Prod. [online]. 2016, vol.26, n.2, pp.385-401. Epub Nov 10, 2015. ISSN 01036513. http://dx.doi.org/10.1590/01036513.146113.

TOLEDO, L. G. DE.; NICOLELLA, G. Índice de qualidade de água em microbacia sob uso agrícola e urbano. Scientia Agricola, v.59, n.1, p.181-186, 2002.

TUCCI, C.E.M. Águas urbanas. Estudos Avançados, v. 22, n. 63, p. 97 -112. 2008.

TSUTIYA, M. T. Redução do custo de energia elétrica em sistemas de abastecimento de água. Rio de Janeiro: Associação Brasileira de Engenharia Sanitária e Ambiental. 2006.

VILLELA, L. C.; CALDAS, V. T.; GAMBA, R. C. Análise microbiológica em águas minerais envasadas em embalagens de $510 \mathrm{~mL}$, comercializadas no município de SantosSP. Rev. Ceciliana, v. 2, n. 1, p. 4-6, 2010.

ZANCUL M. S. Água e saúde. Disponível em: $<$ http://www.cdcc.sc.usp.br/ciencia/artigos /art_32/atualidades.html>. Acesso em: 28 de agosto de 2015 